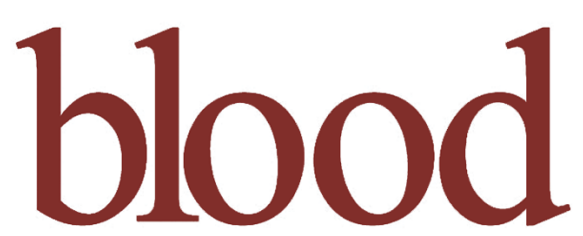

1998 91: $2800-2809$

\title{
CD148 Is a Membrane Protein Tyrosine Phosphatase Present in All Hematopoietic Lineages and Is Involved in Signal Transduction on Lymphocytes
}

Miguel Angel de la Fuente-Garci?a, Josep Maria Nicolás, John H. Freed, Eduard Palou, Andrew P. Thomas, Ramón Vilella, Jordi Vives and Antoni Gayá

Updated information and services can be found at:

http://bloodjournal.hematologylibrary.org/content/91/8/2800.full.html

Articles on similar topics can be found in the following Blood collections

Hematopoiesis and Stem Cells (3153 articles)

Information about reproducing this article in parts or in its entirety may be found online at:

http://bloodjournal.hematologylibrary.org/site/misc/rights.xhtml\#repub_requests

Information about ordering reprints may be found online at:

http://bloodjournal.hematologylibrary.org/site/misc/rights.xhtml\#reprints

Information about subscriptions and ASH membership may be found online at: http://bloodjournal.hematologylibrary.org/site/subscriptions/index.xhtml

Blood (print ISSN 0006-4971, online ISSN 1528-0020), is published weekly by the American Society of Hematology, 2021 L St, NW, Suite 900, Washington DC 20036.

Copyright 2011 by The American Society of Hematology; all rights reserved.

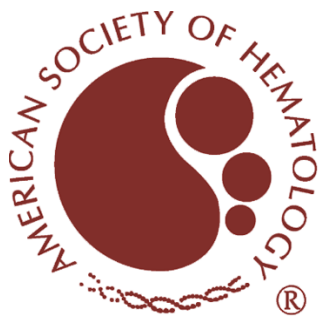




\title{
CD148 Is a Membrane Protein Tyrosine Phosphatase Present in All Hematopoietic Lineages and Is Involved in Signal Transduction on Lymphocytes
}

\author{
By Miguel Angel de la Fuente-García, J osep Maria Nicolás, J ohn H. Freed, Eduard Palou, Andrew P. Thomas, \\ Ramón Vilella, J ordi Vives, and Antoni Gayá
}

\begin{abstract}
Evidence is presented showing that a protein tyrosine phosphatase different from CD45 is present on the membrane of human hematopoietic cells. The molecule recognized by the monoclonal antibody 143-41, which has been classified as CD148 in the VI International Workshop on Leukocyte Differentiation Antigens, was immunopurified and sequenced. The sequence obtained from $\mathrm{N}$-terminus as well as from two different CNBr-digested peptides showed a close identity with a previously described tyrosine phosphatase named HPTP-ף/DEP-1. CD148 is present on all hematopoietic lineages, being expressed with higher intensity on granulocytes than on monocytes and lymphocytes. Interestingly, whereas it is clearly present on peripheral blood lymphocytes, it is poorly expressed on different lymphoid cell lines of $\mathbf{T}$ and $\mathrm{B}$ origin. When this protein tyrosine phosphatase was cocrosslinked with CD3, an inhibition of the nomally
\end{abstract}

$\mathbf{T}$ HE PHOSPHORYLATION of tyrosine residues of proteins is a crucial event in the regulation of cellular processes, including those of proliferation and differentiation. The level of protein phosphorylation is mainly the result of the antagonistic functions of protein-tyrosine kinases (PTKs) and proteintyrosine phosphatases (PTPs). ${ }^{1,2}$ Thus, the activation and inactivation of both enzymes are relevant in determining the functional state of a great variety of intracellular molecules.

In recent years an increasing number of PTPs have been described. Currently over 40 PTPs have been reported. ${ }^{3}$ They have been subcategorized ${ }^{4}$ into three groups: (1) receptor-like PTPs, (2) intracellular PTPs, and (3) dual specific PTPs. The common structural features of the receptor-like PTPs include an extracellular domain of variable length and composition, a single membrane-spanning region, and one or two intracellular catalytic domains.

The interaction of $\mathrm{T}$ cell receptor (TCR) with the appropriate antigen or its stimulation with antireceptor antibodies induces a signal transduction cascade that leads to the expression of a number of genes and eventually to effector functions. One of the earliest biological events after lymphocyte stimulation is the activation of PTKs, which results in tyrosine phosphorylation of

From the Servei d'Immunologia, Servei de Medicina Interna, Hospital Clinic, Barcelona, Spain; the National Jewish Center for Immunology and Respiratory Medicine, Denver, CO; and the Department of Pathology, Anatomy and Cell Biology, Thomas Jefferson University, Philadelphia, PA.

Submitted April 14, 1997; accepted December 9, 1997.

Supported by Grant No. 96/0788 from Fondo de Investigación Sanitaria. M.A.d.l.F.-G. is a recipient of a predoctoral fellowship from Hospital Clínic i Provincial.

Address reprint requests to Antoni Gayà, $M D$, Servei d'Immunologia, Hospital Clínic, Villarroel 170, Barcelona 08036, Spain.

The publication costs of this article were defrayed in part by page charge payment. This article must therefore be hereby marked "advertisement" in accordance with 18 U.S.C. section 1734 solely to indicate this fact.

(c) 1998 by The American Society of Hematology.

0006-4971/98/9108-0021\$3.00/0 observed calcium mobilization was obsenved. This inhibition correlates with a decrease in phospholipase C- $\gamma$ (PLC- $\gamma$ ) phosphorylation and is similar to the one observed with CD45. In addition, it is shown that the crosslinking of the CD148 alone is also able to induce an increase in $\left[\mathrm{Ca}^{2+}\right]_{i}$. This increase is abolished in the presence of genistein and by cocrosslinking with CD45. These data, together with the induction of tyrosine phosphorylation on several substrates, including PLC- $\gamma$, after CD148 crosslinking, suggest the involvement of a tyrosine kinase-based signaling pathway in this process. In conclusion, the data presented show that CD148 corresponds to a previously described protein tyrosine phosphatase HPTP- $\eta$ /DEP-1 and that this molecule is involved in signal transduction in lymphocytes.

(C) 1998 by The American Society of Hematology.

various cellular proteins. Recently it has been observed that the rapid, and generally transient, tyrosine phosphorylation response is the result of a complex and still poorly understood kinase cascade involving at least three families of PTKs: src, syk, and csk (see Zenner et $\mathrm{al}^{5}$ for review). Although leukocytes express a wide variety of PTPs in the cytoplasm, their precise role remains unknown in most of the cases. ${ }^{6}$ Among the PTPs, CD45 is the only membrane PTP that has been described to be involved in the process of signal transduction, ${ }^{7}$ modulating the response to antigen receptor engagement in both $\mathrm{T}^{8}$ and $\mathrm{B}$ lymphocytes. ${ }^{9}$

In this report we present evidence that the recently described CD $148^{10}$ corresponds to a previously described membrane PTP, HPTPh/DEP-1. ${ }^{11-13}$ This molecule is present on all hematopoietic lineages and, in addition to being able to transduce signals by itself, it is also able to modulate the signal transduction through the TCR/CD3 complex in a manner similar to CD45.

\section{MATERIALS AND METHODS}

Cells. Blood samples were obtained from healthy adult donors. Peripheral blood mononuclear cells (PBMCs) were isolated by centrifugation over Ficoll-Hypaque (Pharmacia LKB, Uppsala, Sweden) densitygradient sedimentation. The following cell lines were grown in RPMI plus $10 \%$ fetal calf serum (FCS): CEM, HPB-ALL, HSB2, JURKAT, MOLT-4, RAJI, KM3, NAMALWA, RAMOS, NALM-6, K562, U937, and HL-60.

Monoclonal antibodies (MoAbs). The following MoAbs were produced in our laboratory and ascribed to their CDs through one of the International Workshop on Human Leukocyte Differentiation Antigens (WLDA): CRIS-7 (CD3, IgG2a), 72-5D3 (CD45, IgG2a), and 111-5A1 (CD41, IgG1). MoAbs were purified from ascitic fluid by protein A affinity chromatography. The 143-41 (IgG1) hybridoma was produced in accordance with a previously described method ${ }^{14}$ after immunization of BALB/c mice with PBMCs that had previously been stimulated with phytohemagglutinin (PHA) for 3 days. The following phycoerythrin (PE)-labeled MoAbs were used: HD-37 (CD19), Leu 4 (CD3), and mouse IgG2a control (Becton Dickinson, San Jose, CA).

Immunofluorescence assay. The 143-41 MoAb was labeled with fluorescein following conventional techniques. Cells were washed with immunofluorescence buffer (phosphate-buffered saline [PBS] containing $0.02 \mathrm{mmol} / \mathrm{L}$ sodium azide and $1 \%$ bovine serum albumin [BSA]) 
and incubated with specific MoAb or isotype-matched control MoAb for 30 minutes on ice in immunofluorescence (IF) buffer containing 5\% rabbit serum. For two-color analysis the simultaneous combination of 143-41 fluorescein isothiocyanate (FITC)-conjugated MoAb with a $\mathrm{PE}$-conjugated MoAb, was used. Samples were run on a FACScan flow cytometer (Becton Dickinson). Where applicable, different cell populations (eg, lymphocytes, monocytes, and neutrophils) were identified based on 2-dimensional light scatter characteristics.

Surface biotinylation, immunoprecipitation, specific glycosidases treatment, and immunoblotting. Adult human peripheral blood mononuclear cells were isolated from healthy donors by centrifugation over Ficoll-Hypaque. Cells were prepared for surface biotinylation by washing twice in PBS and resuspending at $5 \times 10^{7}$ cells $/ \mathrm{mL}$ in PBS containing $200 \mu \mathrm{g} / \mathrm{mL}$ Sulfo-NHS-Biotin (Pierce, Rockford, IL). Labeling was allowed to proceed for 30 minutes at $4{ }^{\circ} \mathrm{C}$ and was quenched by incubation for 15 minutes at room temperature with an equal volume of RPMI 1640 medium supplemented with $10 \%$ FCS. Cells were then washed three times in cold PBS and lysed. After 20 minutes on ice, postnuclear extracts were added to $\mathrm{CNBr}$-activated Sepharose 4B (Pharmacia LKB) that had been previously coupled to 143-41 antibody and blocked with 2\% BSA (Sigma Chemical Co, St Louis, MO). After 60 minutes at $4{ }^{\circ} \mathrm{C}$, immunoprecipitates were washed five times in lysis buffer $(0.5 \%$ Nonidet P-40, $10 \mathrm{mmol} / \mathrm{L}$ Tris-HCL, pH 7.40, $150 \mathrm{mmol} / \mathrm{L}$ $\mathrm{NaCl}, 1 \mathrm{mmol} / \mathrm{L}$ EDTA, $1 \mathrm{mmol} / \mathrm{L}$ EGTA, $1 \mathrm{mmol} / \mathrm{L} \mathrm{NaF}, 20 \mathrm{mg} / \mathrm{mL}$ egg white trypsin inhibitor, $1 \mathrm{mg} / \mathrm{mL}$ leupeptin, $1 \mathrm{mg} / \mathrm{mL}$ pepstatin, 1 $\mathrm{IU} / \mathrm{mL}$ aprotinin, and $1 \mathrm{mmol} / \mathrm{L}$ phenylmethyl sulfonyl fluoride [PMSF]) containing $0.05 \%$ sodium dodecyl sulfate (SDS). For deglycosylation, samples of immunoprecipitates were washed and, after boiling, resuspended in the corresponding buffers prepared according to manufacturer's instructions for Neuraminidase $(150 \mathrm{mU} / 50 \mathrm{~mL}$; BoehringerMannheim, Mannheim, Germany), O-Glycosidase (1.5 mU/50 mL, Boehringer-Mannheim) and recombinant $\mathrm{N}$-glycosidase $\mathrm{F}(0.7 \mathrm{mU} / 100$ $\mathrm{mL}$, Boehringer-Mannheim). Overnight digestions at $37^{\circ} \mathrm{C}$ were usually used; however, for Neuraminidase treatment a shorter digestion time ( 2 hours) was used. The glycosidase-treated proteins were run on 5\% sodium dodecyl sulfate-polyacrylamide gel electrophoresis (SDSPAGE) and transferred to Immobilon-P (Millipore Corp, Bedford, MA) in $39 \mathrm{mmol} / \mathrm{L}$ glycine, $48 \mathrm{mmol} / \mathrm{L}$ Tris-base, $1.3 \mathrm{mmol} / \mathrm{L} \mathrm{SDS}$, and $5 \%$ methanol for 2 hours at $60 \mathrm{~V}$. After incubating the filters with blocking solution (10\% nonfat milk protein in PBS) for 2 hours at $4{ }^{\circ} \mathrm{C}$, blots were incubated with streptavidin-peroxidase (Sigma Chemical Co) at 1:2,000 in blocking solution for 1 hour at $20^{\circ} \mathrm{C}$. Filters were washed again with $0.1 \%$ Tween-20 in PBS, and the Western blots were developed using substrate solution $(0.6 \mathrm{mg} / \mathrm{mL}$ diaminobenzidine, $0.1 \%$ hydrogen peroxide $(30 \%)$, and $0.3 \%(\mathrm{wt} / \mathrm{vol}) \mathrm{CoCl}_{2}$ ).

Immunoaffinity purification and protein sequencing. The molecule recognized by $143-41 \mathrm{MoAb}$ was purified following previously described procedures ${ }^{15}$ with modifications. Buffy coats from normal healthy donors were obtained and erythrocytes separated by sedimentation in PBS-2\% Dextran-500 (Pharmacia LKB). Leukocyte-rich supernatants were centrifuged, and about $20 \times 10^{9}$ white blood cells were obtained and washed twice in PBS. Pellets were disrupted in lysis buffer for 30 minutes on ice. Insoluble material was removed by centrifugation at $50,000 \mathrm{~g}$ for 30 minutes at $4^{\circ} \mathrm{C}$ and the supernatant was precleared by passing it sequentially through columns of $\mathrm{CNBr}$-activated Sepharose-4B beads alone and CNBr-activated Sepharose 4B beads coupled with polyclonal mouse Ig or irrelevant IgG1 MoAb. The resulting lysate was then applied to a column of CNBr-activated Sepharose 4B beads $(15 \mathrm{~mL})$ derivatized with MoAb 143.41. The affinity column was washed extensively with modified lysis buffer containing $0.05 \%$ NP40 and then with two column volumes of PBS $0.5 \mathrm{~mol} / \mathrm{L} \mathrm{MgCl}_{2}$. The bound material was eluted with $4 \mathrm{~mol} / \mathrm{L} \mathrm{MgCl}_{2}$ in $\mathrm{PBS}$ and the sample concentrated to $150 \mu \mathrm{L}$ using a Centriprep 30 membrane (AMICON, Beverly, MA) while the buffer was changed to PBS. Cyanogen bromide cleavage of the protein was performed according to a previously described protocol ${ }^{15}: 400 \mathrm{mg}$ of protein were resolved with SDS-PAGE $(5 \%)$ and electroblotted onto nitrocellulose membrane. After transfer, a band visualized by Ponceau S (Sigma Chemical Co), was excised, transferred to a screwcap microvial, and incubated in $300 \mu \mathrm{L}$ of 0.150 $\mathrm{mol} / \mathrm{L} \mathrm{CNBr}$ (Pierce Chemical Co) in 70\% formic acid (vol/vol) (E. Merck, Damstadt, Germany) for 4 hours in the dark, at room temperature. After cleavage, membrane fragment was dried completely with $\mathrm{N}_{2}$ and washed with $200 \mu \mathrm{L}$ water and dried again. The protein fragments were redissolved in Laemmli's sample buffer containing 5\% mercaptoethanol, and the SDS-PAGE for the separation of the peptides was $20 \%$ acrylamide (200:1, acrylamyde:bis), $10 \%$ (vol/vol) glycerol, $0.75 \mathrm{~mol} / \mathrm{L}$ Tris $\mathrm{pH}$ 9.3, and $0.1 \%$ SDS. The gel was aged 2 days, and the running buffer contained $0.1 \mathrm{mmol} / \mathrm{L}$ thioglycolate. After the run, the proteins were blotted onto polyvinylidine difluoride membrane (ProBlott; Applied Biosystems, Inc, Foster City, CA) with transfer buffer ( $48 \mathrm{mmol} / \mathrm{L}$ Tris $\mathrm{pH} \mathrm{9,} 39 \mathrm{mmol} / \mathrm{L}$ Tricine, $1.3 \mathrm{mmol} / \mathrm{L} \mathrm{SDS}$, and $20 \%$ methanol). SDS-PAGE molecular weight standards (Bio-Rad Laboratories, Richmond, CA) were used. The membrane was stained with AmidoBlack ( $0.1 \%$ in $40 \%$ methanol, $1 \%$ acetic acid), washed thoroughly in $\mathrm{H}_{2} \mathrm{O}$, and dried. Two bands were cut out and stored in microvials filled with $\mathrm{N}_{2}$. $\mathrm{NH}_{2}$-terminal sequence analysis of the intact protein and the two protein fragments was performed on an Applied Biosystems 470A/ $120 \mathrm{~A}$ microsequencer.

Phosphatase assay. Substrate preparation and PTP assay were performed with the Malachite Green Phosphatase Assay (Upstate Biotechnology Inc, Lake Placid, NY) as described in the product manual. Affinity purified 143-41 and CD50 molecules (kindly provided by Dr C. Vilardell, H. Clinic, Barcelona, Spain) were diluted in assay buffer (10 mmol/L Tris-HCl, $\mathrm{pH} 7.4)$ and added to microtiter wells with or without the substrate phosphopeptide ( $2 \mathrm{mmol} / \mathrm{L}$, TSTEPQpYQPGENL) allowing enzyme reaction to proceed for 30 minutes. One hundred microliters per well Malachite Green solution was added, and after incubation for 15 minutes the absorbance at $620 \mathrm{~nm}$ was determined with a Titertek Multiscan enzyme-linked immunosorbent assay reader (Flow Laboratories, Rockville, MD). The assay was performed in the presence or absence of $10-\mathrm{mmol} / \mathrm{L}$ sodium orthovanadate (Sigma Chemical Co).

Transfection of COS cells. A full-length cDNA (hp21) encoding the human protein-tyrosine phosphatase $\eta$ (HPTP- $\eta)^{12}$ was the kind gift of Drs H. Honda and H. Hirai, Faculty of Medicine, University of Tokyo, Japan. To examine whether MoAb 143-41 recognizes HPTP- $\eta$ gene product, COS-7 cells were transfected by lipofection. Briefly, $1 \times 10^{6}$ cells in $\log$ phase were washed twice with PBS and incubated in serum-free Dulbecco's modified Eagle's medium containing $30 \mu \mathrm{g} / \mathrm{mL}$ DOTAP (N-[1-(2,3-Dioleoyloxy)propyl]-N,n,n-trimethylammonium methylsulfate; Boehringer Mannheim $\mathrm{GmbH}$, Mannheim, Germany) and $5 \mu \mathrm{g}$ of the pSSRa expression vector with hp21 insert, or $5 \mu \mathrm{g}$ of the pSSRa plasmid alone (mock transfection) at $37^{\circ} \mathrm{C}$ for 6 hours. After 2 days, cells were stained with 143-41 MoAb and FITC-labeled goat antimouse Ig and analyzed on a FACScan flow cytometer (Becton Dickinson).

Analysis of $\left[\mathrm{Ca}^{2+}\right]_{i} . \quad\left[\mathrm{Ca}^{2+}\right]_{\mathrm{i}}$ was measured in individual lymphocytes basically following the method described by Wacholtz and Lipsky. ${ }^{16}$ Briefly, peripheral blood lymphocytes (PBL) were resuspended at a final concentration of $30 \times 10^{6}$ cells $/ \mathrm{mL}$ in RPMI supplemented with $10 \%$ FCS. Cells were loaded with fura- 2 acetoxymethyl ester (fura-2/AM; $2 \mathrm{mmol} / \mathrm{L}$; Calbiochem, San Diego, CA) by incubation for 25 minutes at $37^{\circ} \mathrm{C}$, with gentle shaking. After fura- 2 loading, lymphocytes were incubated with MoAbs (CRIS-7: $10 \mathrm{mg} / \mathrm{mL}$ and $72-5 \mathrm{D} 3,143-41,111-5 \mathrm{~A} 1: 40 \mathrm{mg} / \mathrm{mL}$ ) for 30 minutes at $4^{\circ} \mathrm{C}$. After washing, fura-2-loaded PBL $\left(10^{6}\right.$ cells $)$ were plated on the center of a 25-mm glass coverslip coated with Cell-Tak (Collaborative Biomedical Products, Bedford, MA) in $50 \mathrm{~mL}$ of RPMI medium without FCS. The cells were incubated for 20 minutes at $37^{\circ} \mathrm{C}$ under an atmosphere of $5 \%$ $\mathrm{CO}_{2} /$ air, and washed with incubation buffer composed of $121 \mathrm{mmol} / \mathrm{L}$ 
$\mathrm{NaCl}, 10 \mathrm{mmol} / \mathrm{L}$ HEPES, $5 \mathrm{mmol} / \mathrm{L} \mathrm{NaHCO}_{3}, 4.7 \mathrm{mmol} / \mathrm{L} \mathrm{KCl}, 1.2$ $\mathrm{mmol} / \mathrm{L} \mathrm{KH}_{2} \mathrm{PO}_{4}, 1.2 \mathrm{mmol} / \mathrm{L} \mathrm{MgSO}{ }_{4}, 2 \mathrm{mmol} / \mathrm{L} \mathrm{CaCl}_{2}, 10 \mathrm{mmol} / \mathrm{L}$ glucose, and $0.01 \% \mathrm{BSA}$ at $\mathrm{pH} 7.4$ to remove unattached and nonviable cells. Coverslips with attached lymphocytes were transferred into an open flow chamber $(1 \mathrm{~mL}$, volume) mounted on the heated stage of a Nikon Diaphot-300 inverted epifluorescence microscope. The stage, 40 $\times$ fluor immersion objective (Nikon) and chamber were maintained at $37^{\circ} \mathrm{C}$. $\mathrm{Ca}^{2+}$ mobilization was induced by the crosslinking of cell surface molecules after addition of a second step saturating amount of polyclonal affinity purified goat-antimouse antiserum (GAM; Tago Inc, Burlingame, CA). Cells were considered to respond when $\left[\mathrm{Ca}^{2+}\right]_{\mathrm{i}}$ increased more than $100 \%$ of the basal level. Fluorescence images were obtained by a CCD CH250 camera (Photometrics, Tucson, AZ) and were digitized, stored, and analyzed in an Apple-MacIntosh 840AV computer (Apple Computers Inc, Cupertino, CA). Images were collected alternately at excitation wavelengths of 340 and $380 \mathrm{~nm}(10 \mathrm{~nm}$ bandwidth filters) to excite the $\mathrm{Ca}^{2+}$-bound and $\mathrm{Ca}^{2+}$-free forms of this ratiometric dye, respectively. The emission wavelength was $510 \mathrm{~nm}$ (120 nm bandwidth filter). The integration time for each image was 100 $\mathrm{ms}$, and individual pixels were binned into $2 \times 2$ superpixels at read out from the charge coupled device detector to improve signal to noise. To minimize photobleaching, a computer-controlled shutter was used to limit the exposure of the cells to excitation light. $\left[\mathrm{Ca}^{2+}\right]_{\mathrm{i}}$ values were calculated on a single-cell basis from the 340- to 380-nm fluorescence ratios at each time point as described previously. ${ }^{17,18}$ All images were checked for movement artifacts, and a reference point was used to obtain true coregistration of the 340- and 380-nm images. At the end of each experiment, cells were exposed to ionomicyn $(10 \mathrm{mmol} / \mathrm{L})$ and $\mathrm{MnCl}_{2}$ for 20 minutes. This treatment quenches the fluorescence of the intracellular $\mathrm{Ca}^{2+}$-sensitive fura-2, leaving the residual fluorescence at each wavelength because of cell autofluorescence and any $\mathrm{Ca}^{2+}$ insensitive forms of the dye. The residual fluorescence was measured over the same region of each cell as the $\mathrm{Ca}^{2+}$-dependent fluorescence.

Statistics. Standard statistical methods from SPSS Statistical Analysis System V4.0+ (SPSS, Chicago, IL) were used. Paired two-tailed $t$-tests were used to analyze the differences between conditions in each experiment. All variables were expressed as mean \pm standard error (SE), and a significance level of $P<.05$ was used.

Cell stimulation and tyrosine phosphorylation analysis. Cells $(50 \times$ $\left.10^{6}\right)$ were incubated with the different MoAbs $(10 \mu \mathrm{g})$ for 15 minutes at $4{ }^{\circ} \mathrm{C}$ followed by the addition of crosslinking rabbit antimouse Igs $(5$ $\mu \mathrm{g})$. Incubation was terminated after different periods of time by the addition of $1 \mathrm{~mL}$ of ice-cold stop buffer $(50 \mathrm{mmol} / \mathrm{L}$ HEPES, 150 $\mathrm{mmol} / \mathrm{L} \mathrm{NaCl}, 100 \mathrm{mmol} / \mathrm{L} \mathrm{NaF}, 10 \mathrm{mmol} / \mathrm{L}$ EDTA, $10 \mathrm{mmol} / \mathrm{L}$ $\mathrm{Na}_{4} \mathrm{P}_{2} \mathrm{O}_{7}, 2 \mathrm{mmol} / \mathrm{L}$ sodium pervanadate, $2 \mathrm{mmol} / \mathrm{L}$ PMSF, $10 \mathrm{mg} / \mathrm{mL}$ aprotinin, $10 \mathrm{mg} / \mathrm{mL}$ pepstatin, $1 \mathrm{mg} / \mathrm{mL}$ leupeptin, $100 \mathrm{mmol} / \mathrm{L}$ PAO). Cells were pelleted and lysed with stop buffer containing $1 \%$ NP-40. Proteins were separated by SDS-PAGE and transferred to nitrocellulose membranes. Phosphotyrosine-containing proteins were probed with antiphosphotyrosine MoAb PY-20 from Santa Cruz Biotechnology (Santa Cruz, CA) and horseradish peroxidase-conjugated rabbit antimouse and visualized by fluorography with enhanced chemiluminescence reagent (Amersham, Buckinghamshire, UK).

Immunoprecipitation of phospholipase $C$ - $\gamma 1$. For immunoprecipitation experiments, cell lysates of $25 \times 10^{5}$ stimulated cells were prepared as described previously. Precleared lysates were incubated overnight with $1 \mu \mathrm{g}$ of anti-PLC-g1 MoAb (UBI Inc, Lake Placid, NY). Immunoprecipitates were recovered by incubation with $20 \mu \mathrm{L}$ of Protein A-Sepharose beads for 120 minutes at $4^{\circ} \mathrm{C}$ and washed three times in lysis buffer. The proteins were then eluted and dissolved by boiling for 5 minutes in Laemmli sample buffer and subsequently resolved by SDS-PAGE. Western blot analysis was then performed using PY20 antiphosphotyrosine antibody (UBI Inc), biotinylated goat antimouse (Sigma Chemical Co), and avidin-peroxidase (Sigma Chemical Co) as described above. Next, membranes were stripped of primary antibody with stripping buffer (100 mmol/L 2-ME, $2 \%$ SDS, Tris-Cl $65 \mathrm{mmol} / \mathrm{L}$, $\mathrm{pH}=7.5$ ) washed and reprobed with anti-PLC- $\gamma 1 \mathrm{MoAb}$ (UBI Inc).

\section{RESULTS}

Phenotypic and immunochemical characterization of CD148. With the aim of producing MoAbs defining new membrane proteins, several MoAbs were obtained in our laboratory. One of them, MoAb 143-41, defined a molecule present on peripheral blood cells that shows its highest expression on granulocytes, being present at intermediate intensity on monocytes and lymphocytes (Fig 1A, left). Its expression on red blood cells and platelets was even lower than the one observed on those cells (Fig 1A, right). This molecule was detected on both $\mathrm{T}$ and $\mathrm{B}$ lymphocytes as determined by double immunofluorescence with FITC-labeled 143-41 and PE-labeled CD3 and CD19 (Fig 1B). The reaction of 143-41 MoAb with different hematopoietic cell lines was also tested (Fig 2). Thus, CD148 showed a clear reaction with cell lines of myeloid origin (K562, U937, and HL-60) and with some B-cell lines (Raji, KM3, Nalm-6), whereas this was weakly expressed on Namalwa and Ramos, also of B-cell origin. Surprisingly, and in contrast with the clear expression observed on $\mathrm{CD}^{+}$lymphocytes, it was not detected

A

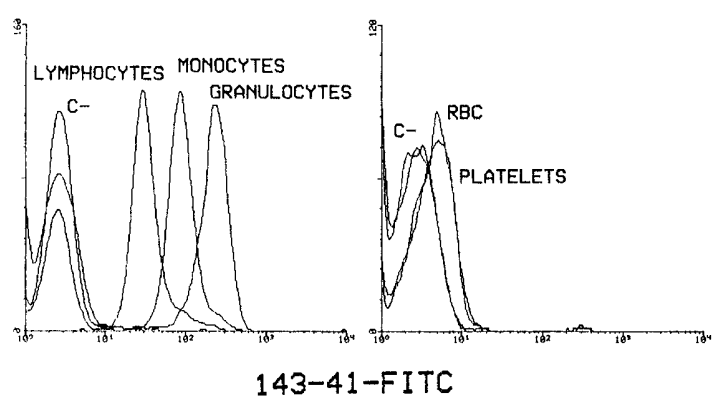

B
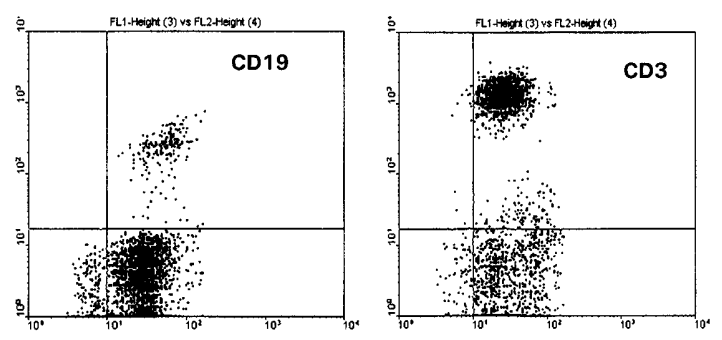

Fig 1. Flow cytometric analysis of human hematopoietic cell lineages. Whole blood was stained with fluoresceinated-CD148 as described in Materials and Methods and analyzed on a FACScan flow cytometer. (A) Erythrocytes and platelets were analyzed after selecting cell populations by side scatter and forward size. In parallel, after washing, erythrocytes were lysed by incubating with lysis buffer and the different leukocyte populations were selected on basis of cell scatter and forward size characteristics. Histograms for fluorescence of simultaneously stained lymphocytes, monocytes, and granulocytes have been superimposed. (B) PBL were obtained from nomal healthy donors by Ficoll-Hypaque gradient density centrifugation and lymphocyte populations were analyzed by two color fluorescence by using fluoresceinated 143-41 MoAb and comercially available PElabeled CD3 and CD19 MoAb. The appropiate negative control FTTCand PE-labeled MoAbs were used to establish the marker position. The staining intensity of PE-labeled cells is shown in the vertical axis with 143-41-FTC staining on the horizontal axis. 


\section{LYMPHOID}

T CELLS
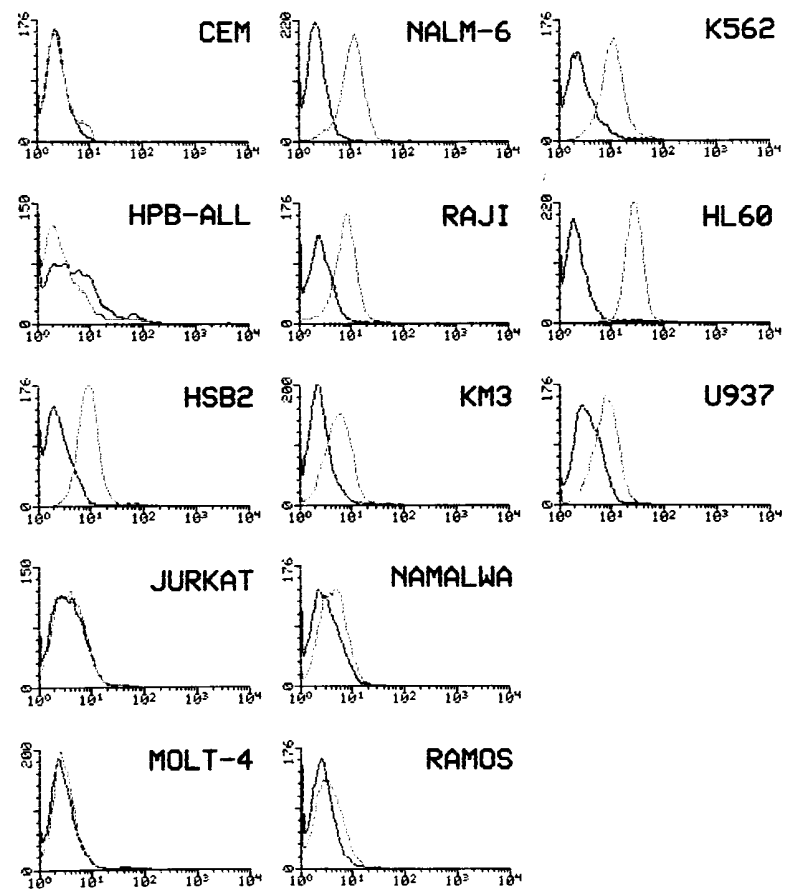

Fig 2. Expression patterns of CD148 on different cell lines of myeloid and lymphoid origin. The 143-41 MoAb was assayed for their binding to cell lines by first incubating the cells with a saturating amount of antibody and, after washing, cells were incubated with a FITC-labeled goat antimouse antibody (-). Cells were also stained with a control isotype-matched antibody. The staining intensity of FITC-labeled cells is shown on the horizontal axis with the number of cells on the vertical axis.

on T-cell lines (CEM, HPB-ALL, Jurkat, and MOLT-4) with the exception of HSB-2.

Although this MoAb was analyzed during the IV WLDA it could not be clustered. During the work of the VI WLDA held recently in Kobe, another MoAb (A3) with a similar pattern of reaction was detected. In basis of the comparative analysis of this antibody with our MoAb 143-41, a new cluster of differentiation could be defined: CD148. ${ }^{10}$

To further characterize this molecule a thoroughly biochemical characterization was performed. The molecule was immunoprecipitated, and before and after digestion with neuraminidase, $\mathrm{O}$-glycanase, and N-glycanase it was subjected to electrophoresis in reducing conditions and analyzed by immunoblotting, as described in Materials and Methods. As can be observed in Fig 3, CD148 appeared before treatment as a broad band with an apparent molecular weight of $240 \mathrm{kD}$. Treatment of purified CD148 with the various glycosidases led to alterations in the electrophoretic mobility of the protein. Thus, after treatment with $\mathrm{N}$-glycosidase $\mathrm{F}$, the molecular weight of CD148 was shifted to a much smaller size in Western blot analysis, indicating that the molecule recognized by 143-41 was a glycoprotein containing Asn-linked carbohydrate and that the molecular weight of this molecule was, for the most part,

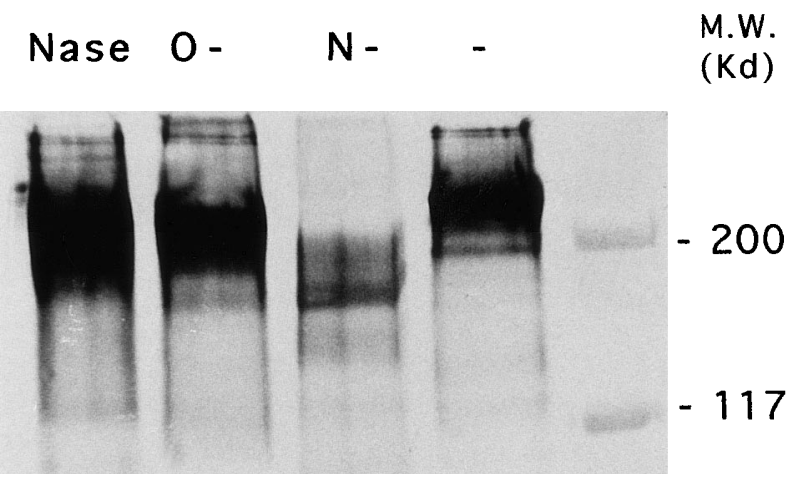

Fig 3. Immunochemical characterization of CD148 molecule. Adult human PBMCs were surface biotinylated and CD148 molecule was immunoprecipitated by using 143-41-coupled CNBr-activated Sepharose 4B. Sample aliquots were subjected to treatment with $\mathrm{N}$-endoglycosidase $\mathbf{F}$ (lane 3), O-endoglycosidase (lane 2), and neuraminidase (lane 1) as described in the Materials and Methods. Next, samples were analyzed on a $5 \%$ SDS-polyacrylamide gel under reducing conditions before (lane 4 ) and after glycanase treatment (lanes 1, 2, and 3), followed by electrophoretic transfer of proteins onto Immobilon-P. After blocking and incubating with streptavidinperoxidase, the Westem blots were developed using diaminobenzidine with cobalt enhancement.

modified by the $\mathrm{N}$-glycosylation. O-Glycanase treatment also affected the electrophoretic mobility of the CD148 by decreasing its apparent molecular weight under reducing conditions. In addition, a slight decrease in the electrophoretic mobility was observed after treatment with neuraminidase suggesting the existence of sialic acid residues. The reaction of CD148 with Maackia amurensis and Sambucus nigra L biotinylated lectins, confirmed this presence and showed that they are linked in both $\alpha(2-3)$ and $\alpha(2-6)$ to galactose (data not shown).

Protein sequencing and identification as HPTP- $/$ DEP-1. CD148 was purified by immunoaffinity chromatography from leukocyte membranes and subjected to $\mathrm{N}$-terminal sequencing. After digestion of $\mathrm{CD} 148$ with $\mathrm{CNBr}$, several peptides were obtained, two of them being subjected to N-terminal sequencing. The sequences obtained are shown in Fig 4. A complete homology of these sequences with the recently described PTP HPTP- $-\eta^{12}$ or DEP- $1^{13}$ was detected. As can be seen in Fig 4, in all the positions in which a clear sequence was obtained, an identity of sequence was observed. In both $\mathrm{CNBr}$-derived peptides it was observed that the sequence started after a methionine residue in the sequence of the PTP, in agreement

\begin{tabular}{|c|c|c|}
\hline $\begin{array}{l}\text { HPTP } / \text { DEP- } 1 \text { (485- } \\
\text { CD148 peptide } 1\end{array}$ & $\rightarrow$ & $\begin{array}{r}\text { MHITQEGAGNSRVEITTNQ } \\
\text { HITQEGAGNSRVEITTXQ }\end{array}$ \\
\hline $\begin{array}{l}\text { HPTP } / \text { DEP-1 } \\
\text { CD148 peptide } 23-\end{array}$ & $\rightarrow$ & $\begin{array}{l}\text { MASFDCEVVPKEPALVLKW } \\
\text { ASFDXXVVPKEPALVLKX }\end{array}$ \\
\hline $\begin{array}{l}\mathrm{PTP} / \mathrm{DEP}-1 \quad 139 / 36 \\
\mathrm{D} 148 \mathrm{~N} \text {-terminal }\end{array}$ & $\rightarrow$ & $\begin{array}{l}\text { AGGTPSPIPDPS } \\
\text { AGGTPSXIPDXS }\end{array}$ \\
\hline
\end{tabular}

Fig 4. Identity between CD148 $\mathrm{N}$ terminal and peptide sequence and deduced HPTP-h/DEP-1 protein sequence from the CDNA. Numbering of HPTP-y/DEP-1 amino acid positions are from Honda et al12 and Ostman et al. ${ }^{13}$ Assignment of $X$ in the CD148 sequence represents nonidentifiable signal in the sequence analysis. 
with the existence of a point of cleavage for $\mathrm{CNBr}$. From the $\mathrm{N}$-terminal sequence data we obtained, it should be noted that the mature $\mathrm{N}$ terminus corresponds to Ala 36 and not to Thr 39 (HPTP- $\eta)^{12}$ or Gly 37 (DEP-1). ${ }^{13}$

To confirm that the molecule recognized by $143-41 \mathrm{MoAb}$ corresponds to the previously described protein tyrosine phosphatase HPTP- $\eta$ /DEP-1 two different approaches were undertaken. First, hp21, a full length HPTP- $\eta$ cDNA was used to transfect COS-7 cells. When stained with 143-41 MoAb, whereas mock-transfected COS-7 cells were negative (Fig 5A), the COS-7 cells transfected with the HPTP- $\eta$ cDNA showed a clear positive reaction (Fig $5 \mathrm{~B}$ ). In addition, the phosphatase activity of CD148 was analyzed by testing its ability to release phosphate groups from a tyrosine phosphorylated peptide. As can be observed in Fig 6 a clear tyrosine phosphatase activity was observed when immunopurified CD148 was tested. This activity was clearly diminished in the presence of sodium orthovanadate, a PTP inhibitor. No PTP activity was detected when a similarly immunopurified molecule, CD50, was tested in the same assay.

$\mathrm{Ca}^{2+}$ mobilization after CD3, CD148, and CD45 crosslinking. Previous studies had shown that CD3-induced $\mathrm{Ca}^{2+}$ mobilization is modulated by the tyrosine phosphatase activity of CD45 when both molecules were cocrosslinked. ${ }^{7}$ Based on the fact that CD148 was identified as a PTP expressed on the membrane of lymphocytes, we evaluated whether CD148 could modify the activation induced by CD3 crosslinking. Therefore, PBL were loaded with fura-2/AM, and $\mathrm{Ca}^{2+}$ mobilization after cell stimulation was analyzed by computer-aided fluorescence imaging. Figure 7 depicts the mean changes of $\left[\mathrm{Ca}^{2+}\right]_{\mathrm{i}}$ including all PBL populations after crosslinking the $\mathrm{CD} 3$ molecule. These data are normalized to the basal values before the addition of affinity purified GAM, and $\mathrm{Ca}^{2+}$ changes were measured in individual cells. Mean $\left[\mathrm{Ca}^{2+}\right]_{\mathrm{i}}$ increased from a baseline of $71 \pm 4 \mathrm{nmol} / \mathrm{L}$ to $163 \pm 15 \mathrm{nmol} / \mathrm{L}$ after addition of the CD3 crosslinking agent. In agreement with previous results, ${ }^{7}$ we observed a significant decrease in the CD3-induced response because of CD45 cocrosslinking. Moreover, when CD3 was
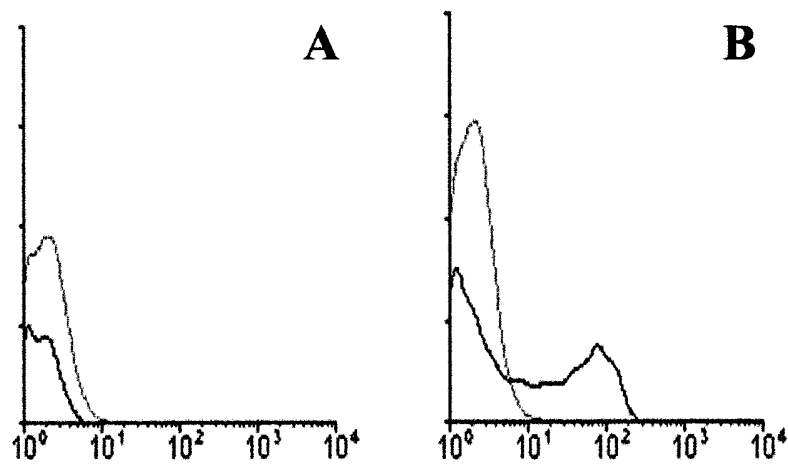

\section{3-41-FITC}

Fig 5. Immunofluorescence analysis of mock-transfected COS-7 cells (A) or COS-7 cells transfected with HPTP- $\eta$ CDNA (B). COS-7 cells were transfected with hp21 clone encoding HPTP- $\eta$ or plasmid only and stained with 143-41-FrTC as described in the Materials and Methods.

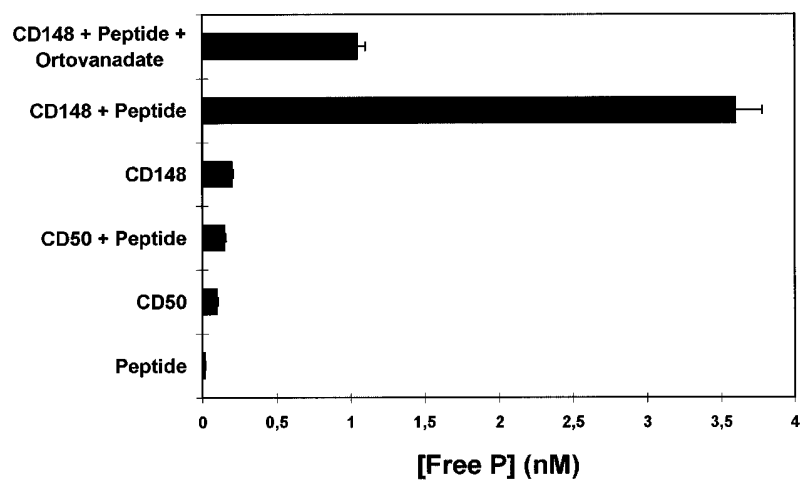

Fig 6. PTP activity of purified CD148 molecule. Affinity purified CD148 molecule was incubated with a tyrosine phosphorylated syntethic peptide (TSTEPQPYQPGENL). The amount of free phosphate released as inorganic phosphate in the absence or presence of vanadate was measured by the Malachite Green Phosphatase Assay (UBI) and it is shown as $\mathrm{nmol} / \mathrm{L}$ concentration. Affinity purified CD50 molecule was used as a negative control.

cocrosslinked with CD148, we also observed a clear reduction in the mean peak $\left[\mathrm{Ca}^{2+}\right]_{\mathrm{i}}$ response $(P<.05 ; \mathrm{n}=5$ experiments; Fig 7), suggesting that the PTP activity of CD148 could modulate signals transduced through the CD3 complex, similarly to CD45. Interestingly enough, when CD148 alone was crosslinked, we observed an increase in the mean $\left[\mathrm{Ca}^{2+}\right]_{i}$, reaching a mean peak of $130 \pm 8 \mathrm{nmol} / \mathrm{L}$, which was delayed and significantly lower $(P<.05, \mathrm{n}=6$ in both experiments; Fig 7) when compared with $\mathrm{CD} 3$ crosslinking stimulation. In addition, to determine the role of tyrosine phosphorylation in $\left[\mathrm{Ca}^{2+}\right]_{\mathrm{i}}$ increase induced by CD148 stimulation we tested whether the phosphatase activity of CD45 could abolish this effect when both molecules were cocrosslinked, as has been described in other tyrosine kinase-mediated activations. ${ }^{19}$ As can be observed in Fig 8 , the $\left[\mathrm{Ca}^{2+}\right]_{\mathrm{i}}$ increase induced by CD148 crosslinking was inhibited when CD45 was cocrosslinked with CD148.

Because the mean $\left[\mathrm{Ca}^{2+}\right]_{\mathrm{i}}$ kinetics may be influenced either by the percentage of responding cells, appearance of unsynchronized responses, or variable intensity response, ${ }^{20}$ individual cell measurements of the $\left[\mathrm{Ca}^{2+}\right]_{\mathrm{i}}$ changes after CD3, CD45, and CD148 crosslinking were also evaluated (Fig 8). For the analysis of the single cell responses, we considered a response significant when the $\mathrm{Ca}^{2+}$ mobilization induced by crosslinking was at least twice the $\left[\mathrm{Ca}^{2+}\right]_{\mathrm{i}}$ of the basal level. In this sense, anti-CD3 induced a rapid and significant (within 1 minute) $\left[\mathrm{Ca}^{2+}\right]_{\mathrm{i}}$ increase in $65 \%$ of cells, with these cells exhibiting a mean peak $\left[\mathrm{Ca}^{2+}\right]_{\mathrm{i}}$ of $414 \pm 10 \mathrm{nmol} / \mathrm{L}$. This was followed by smaller $\left[\mathrm{Ca}^{2+}\right]_{\mathrm{i}}$ oscillations, especially in those cells with a higher $\left[\mathrm{Ca}^{2+}\right]_{i}$ peak (polytopic response). The asynchronous $\left[\mathrm{Ca}^{2+}\right]_{\mathrm{i}}$ oscillations observed at the single cell level are responsible for the sustained phase of the $\left[\mathrm{Ca}^{2+}\right]_{\mathrm{i}}$ changes identified in cell suspension experiments. The reduction in the mean $\left[\mathrm{Ca}^{2+}\right]_{\mathrm{i}}$ response observed after CD3 $+\mathrm{CD} 45$ cocrosslinking was basically caused by a decrease in the immediate $\mathrm{Ca}^{2+}$ mobilization, affecting an average of $69 \%$ of the responding cells. As may also be observed in Fig 8, crosslinking of CD45 alone did not induce any significant modification of the $\left[\mathrm{Ca}^{2+}\right]_{\mathrm{i}}$ levels. With respect to the inhibitory effect of CD148 on CD3-induced 


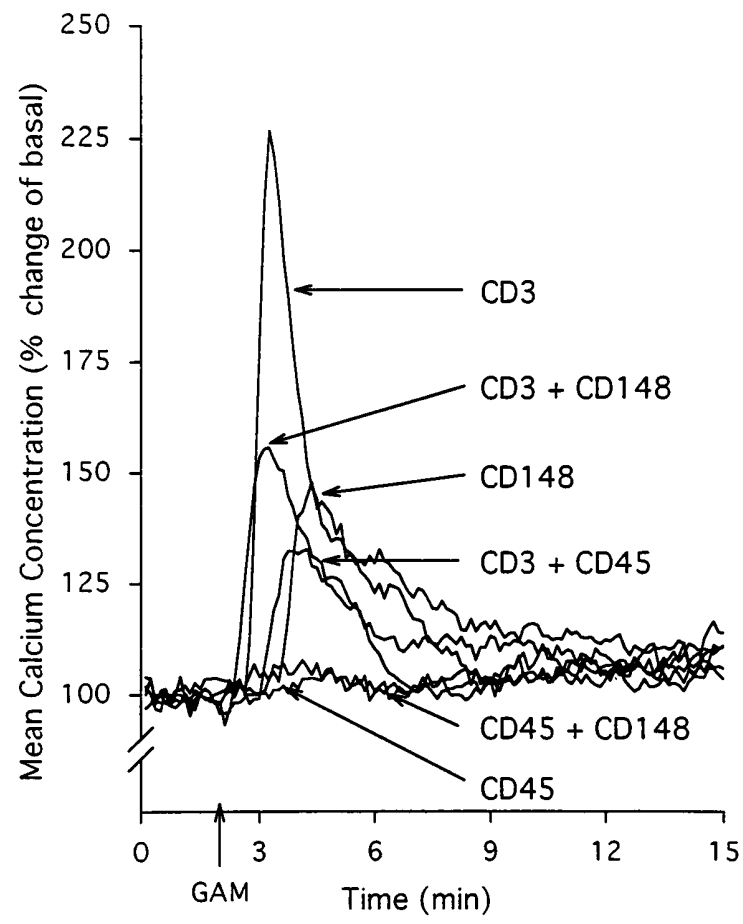

Fig 7. Calcium mobilization induced after CD3, CD148, and CD3+CD148 crosslinking. Peripheral blood lymphocytes were loaded with fura-2, and $\left[\mathrm{Ca}^{2+}\right]$ was measured as described in the Materials and Methods. Cells were incubated 30 minutes at $4^{\circ} \mathrm{C}$ with the different MoAbs (CD3, $10 \mu \mathrm{g} / \mathrm{mL}$; 143-41, $50 \mu \mathrm{g} / \mathrm{mL}$; CD45, $50 \mu \mathrm{g} / \mathrm{mL}$ ) and adhered to Cell-Tak coated coverslips. After establishing baseline values, a saturating amount of GAM was added to prewarmed samples (arrow). $\left[\mathrm{Ca}^{2+}\right]_{i}$ was measured every 5 seconds for 15 minutes on a single-cell basis in a computer-aided fluorescence imaging. The average curve of a minimum of $\mathbf{2 0 0}$ individual cells for each condition of at least four independent experiments are shown. Calcium changes are expressed as the percentage change from basal.

stimulation, we observed a decrease in the immediate response in $35 \%$ of the cells.

Individual responses to CD148 crosslinking exhibited a synchronized, more than twofold increase in $\left[\mathrm{Ca}^{2+}\right]_{\mathrm{i}}$ in $39 \%$ of the cells (Fig 8). This increase, which was delayed (1 minute) if it was compared with the rapid response observed after CD3 crosslinking, was significantly different from the levels observed in the presence of an isotype matched control MoAb (111-5A1, CD41; data not shown). Likewise, no response was observed after adding GAM to the sample. The inhibitory effect of CD45 cocrosslinking was observed to affect $80 \%$ of CD148 responding cells, affecting especially the early phase of the response (Fig 8). These data suggest that the crosslinking of CD148 could induce $\mathrm{Ca}^{2+}$ mobilization through tyrosine phosphorylation processes. To better characterize this point, the response to CD148 crosslinking in the presence of a known protein tyrosine kinase inhibitor, genistein, was analyzed. The data presented in Fig 9A show that genistein clearly inhibits the $\mathrm{Ca}^{2+}$ mobilization induced by CD148 croslinking. When individual cell measurements of the $\left[\mathrm{Ca}^{2+}\right]_{\mathrm{i}}$ changes were analyzed after CD148 crosslinking in the absence (Fig 9B) or presence of genistein $75 \mu \mathrm{mol} / \mathrm{L}$ (Fig 9C) it was confirmed that the inhibition observed in the presence of genistein was real and not caused by the induction of unsynchronized responses. The inhibitory effect of genistein affected $70 \%$ of CD148 responding cells, mainly during the early phase of the response (Fig 9C).

Induction of tyrosine phosphorylation by CD148 crosslinking. The results of the CD45 cocrosslinking and genistein experiments led us to investigate whether specific tyrosine phosphorylation events were associated with anti-CD148triggered $\mathrm{Ca}^{2+}$ mobilization. Thus, cells previously coated with CD3, CD148, or both were lysed in SDS sample buffer at various times after addition of rabbit antimouse antiserum and tyrosine-phosphorylated proteins were detected by immunoblotting. As shown in Fig 10, and as it has been exhaustively described, a rapid increase in the phosphotyrosine content of several proteins was observed after CD3 crosslinking (Fig 10A, lanes 2 and 3). In addition, phosphorylation of several substrates after CD148 crosslinking was also evident (Fig 10A,

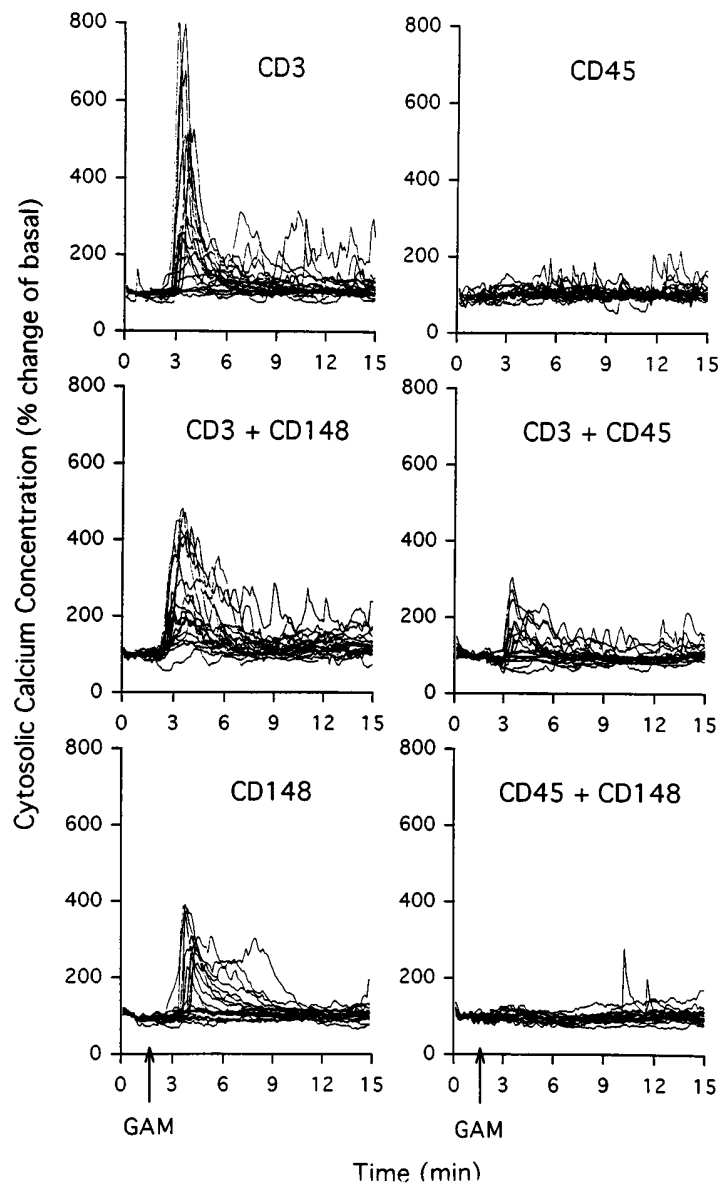

Fig 8. Fluorescence imaging of $\left[\mathrm{Ca}^{2+}\right]_{i}$ responses from individual cells after CD3, CD148, and CD3+CD148 crosslinking. Cells previously loaded with fura-2 ( $2 \mu \mathrm{mol} / \mathrm{L}$ ), were incubated with the corresponding antibody (CD3, $10 \mu \mathrm{g} / \mathrm{mL}$; 14341, $40 \mu \mathrm{g} / \mathrm{mL}$; CD45, $40 \mu \mathrm{g} / \mathrm{mL}$ ) for 30 minutes at $4^{\circ} \mathrm{C}$. After washing, cells were plated on Cell-Takcoated glass coverslips. After establishing baseline values, saturating amount of polyclonal GAM was added to prewarmed samples. $\left[\mathrm{Ca}^{2+}\right]_{i}$ was measured every 5 seconds for 15 minutes in every cell. Calcium changes are expressed as the percentile change of basal. A total of $\mathbf{2 0}$ cells representative of each condition are shown. Each line represents an individual cell. 

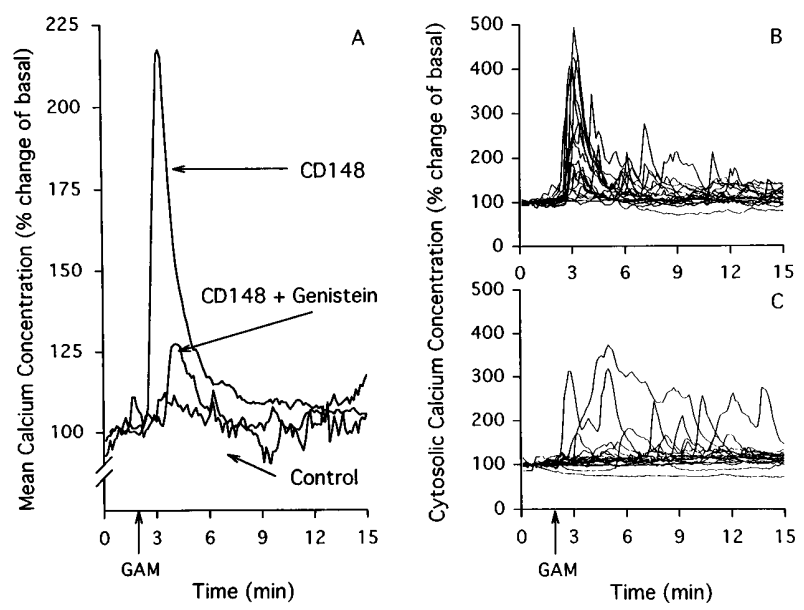

Fig 9. Effect of Genistein on calcium mobilization induced by CD148 crosslinking. Peripheral blood lymphocytes were loaded with fura-2, and $\left[\mathrm{Ca}^{2+}\right]$ was measured as described in the Materials and Methods. Cells were incubated 30 minutes at $4^{\circ} \mathrm{C}$ with $50 \mathrm{mg} / \mathrm{mL}$ of CD148 and adhered to Cell-Tak-coated coverslips. After establishing baseline values, a saturating amount of GAM was added in the absence or presence of $75 \mathrm{mmol} / \mathrm{L}$ Genistein to prewarmed samples (arrow). $\left[\mathrm{Ca}^{2+}\right]_{i}$ was measured every 5 seconds for 15 minutes on a single-cell basis in a computer-aided fluorescence imaging. (A) The average curve of a minimum of 200 individual cells for each condition of at least four independent experiments are shown. Calcium changes are expressed as the percentage change from basal. Fluorescence imaging of $\left[\mathrm{Ca}^{2+}\right]$ responses from 20 individual cells, after CD148 crosslinking, in the absence (B) or the presence (C) of genistein (75 $\mu \mathrm{mol} / \mathrm{L})$. Each line represents an individual cell.

lanes 4 and 5). These results are in agreement with those that have been presented previously and suggest that the $\mathrm{Ca}^{2+}$ mobilization induced by CD148 crosslinking could be mediated by tyrosine phosphorylation events.

On the other hand, and taking into account the tyrosine phosphatase activity of CD148, we were interested to know whether the CD148-induced inhibition of CD3-mediated $\mathrm{Ca}^{2+}$ mobilization was caused by specific dephosphorylation event(s). The pattern of protein tyrosine phosphorylation after activation of human lymphocytes with CD3 crosslinking was modified when CD148 was cocrosslinked to this receptor (Fig 10A, lanes 6 and 7). Thus, a selective inhibition of some substrate was detected, which could be related with the phosphatase activity of CD148. Taking into account the previously established relationship between calcium mobilization and tyrosine phosphorylation of phospholipase $\mathrm{C} \gamma$ (PLC- $\gamma$ ) we were interested in analyzing the phosphorylation status of this enzyme after cell stimulation. Cells coated with CD3, CD148, or both were stimulated with rabbit antimouse Ig and after cell lysis at different times, PLC- $\gamma$ was immunoprecipitated. The immunoblotting with an antiphosphotyrosine antibody (Fig 10B) showed that, whereas after stimulating with CD3 and CD148 an increase in tyrosine phosphorylation of PLC- $\gamma$ was observed, a clear decrease was detected when both CD3 and CD148 were cocrosslinked. By reprobing with an anti-PLC- $\gamma$ it was observed that the same quantity of PLC- $\gamma$ was loaded on each lane. These results are in agreement with the data provided by $\mathrm{Ca}^{2+}$ mobilization analysis.

In addition, it was observed that cotriggering of CD3 with
CD148 resulted in an increase in protein tyrosine phosphorylation in some other proteins. This increase in the phosphorylation pattern was particularly evident on a $56-\mathrm{kD}$ substrate.

\section{DISCUSSION}

During recent years there has been an increase in the description of new PTPs, ${ }^{3}$ although the majority of these PTPs have been mainly related to activities of the central nervous system. In contrast, although the number of PTKs involved in lymphocyte signal transduction has also grown, this has not been the case for the number of PTPs involved in this process. In addition to the cytoplasmic PTPs involved in lymphocyte signaling, just one membrane PTP, CD45, is known to influence the signaling process after antigen receptor engagement (see Streuli ${ }^{21}$ for review). In this paper, we have presented evidences showing that in addition to CD45, there is another PTP on the

A

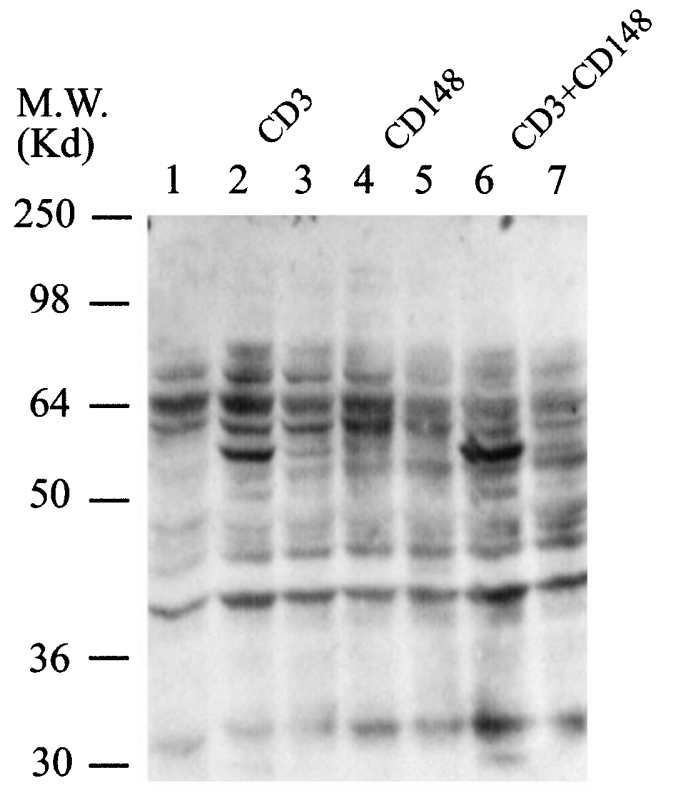

B

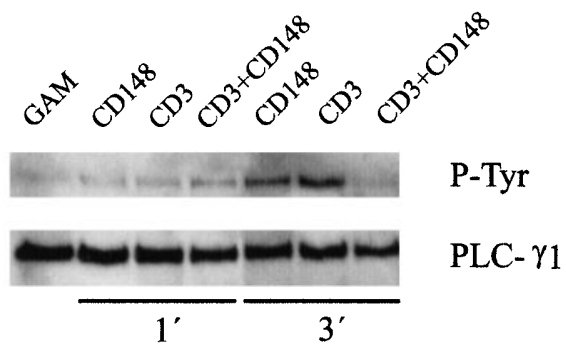

Fig 10. Protein tyrosine phosphorylation induced by CD148 crosslinking. (A) Cells were incubated without (lane 1) or with (lanes 2 to 7) $10 \mu \mathrm{g}$ of the different monoclonal antibodies for $\mathbf{1 5}$ minutes at $4^{\circ} \mathrm{C}$ followed by the addition of crosslinking rabbit antimouse Igs. Incubation was terminated after 1 minute (lanes 2, 4, and 6) and 5 minutes (lanes 3, 5, and 7). Proteins were resolved by SDS-PAGE followed by antiphosphotyrosine immunoblotting. (B) PLC- $\gamma 1$ was immunoprecipitated from cells stimulated during 1 and 3 minutes and analyzed by Westem blot with an antiphosphotyrosine antibody and, after stripping, with an anti-PLC- $\gamma 1$. 
lymphocyte membrane that could be able to modulate the signaling process after CD3 crosslinking. Thus, we have observed that the cocrosslinking of the molecule recognized by the MoAb 143-41, together with CD3 inhibits the subsequent $\left[\mathrm{Ca}^{2+}\right]_{\mathrm{i}}$ increase. Our results show that this molecule is a membrane protein tyrosine phosphatase identical to a recently described HPTP called HPTP- $\eta^{12}$ or DEP- $1 .{ }^{13}$ This phosphatase is present on the membrane of all the hematopoietic cells and it has been classified as CD148 during the last VI WLDA. ${ }^{10}$ Within the lymphoid cells, it is preferentially expressed on B cells, memory $\mathrm{T}$ lymphocytes, and mature thymocytes (A. Gayá, unpublished observations). In contrast, its expression on hematopoietic cell lines is heterogeneous. Thus, whereas it is clearly expressed on myeloid cell lines and on the majority of B-cell lines tested it is absent from the majority of T-cell lines analyzed. Although this pattern of distribution could seem contradictory there are other molecules that display a similar pattern of distribution. Thus, CD26, which is clearly present on all mature $\mathrm{T}$ lymphocytes is absent from T-cell lines with the exception of HSB-2. ${ }^{22}$

We have presented several pieces of evidence showing that CD148 is identical to HPTP- $\eta^{12}$ and DEP-1. ${ }^{13}$ First, the sequences we obtained by protein sequencing and the previously published cDNA sequences of HPTP- $-\eta^{12}$ and DEP- $1^{13}$ are identical. These sequences include an $\mathrm{N}$-terminal fragment of 18 amino acids as well as two different $\mathrm{CNBr}$-derived peptides of $18 \mathrm{aa}$. We consider those sequences as identical at all of the resolved positions, and the nonresolved positions can be explained by technical problems inherent in the sequencing process. The most interesting aspect of these data is the determination that the $\mathrm{N}$-terminal residue of the mature protein corresponds to an Ala and not to the previously proposed $\mathrm{Thr}^{12}$ or Gly. ${ }^{13}$ Second, when COS-7 cells were transfected with a plasmid (hp21) containing a HPTP- $\eta$ encoding cDNA clone, ${ }^{12}$ a clear reaction with 143-41 MoAb was observed. Third, by using an immunopurified preparation of CD148 molecule, obtained from leukocyte membranes, it was possible to determine its capacity to release free phosphate groups from a tyrosine phosphorylated peptide, thus, confirming its tyrosine phosphatase activity. The immunochemical characterization of CD148 molecule confirmed that this molecule contains both $\mathrm{O}$ - and $\mathrm{N}$-linked carbohydrates. From the analysis with glycosidases it could be deduced that the major part of carbohydrates are $\mathrm{N}$-linked. This is in agreement with the 34 potential sites for $\mathrm{N}$-linked glycosilation determined from the cDNA sequence ${ }^{10,11}$ and the data presented by Honda et $a^{12}$ on $\mathrm{N}$-glycosidase $\mathrm{F}$ treatment of HPTP- $\eta$. Concerning the apparent molecular weight of HPTP- $\eta$, differences have been described among several cell lines ${ }^{11,12}$ varying from $250 \mathrm{kD}$ (HL60) to $230 \mathrm{kD}$ (F-36P) or $220 \mathrm{kD}$ (F-36E). Taking into account that CD148 molecule was obtained from a heterogeneous population of cells, the broad band around $240 \mathrm{kD}$ we have observed both by immunoprecipitation and immunoafinity purification could include all the forms previously mentioned, suggesting the existence of a certain level of heterogeneity in the expression of this phosphatase among several cellular lineages.

HPTP- $\eta$ or DEP-1 is a recently described receptor PTP, the extracellular portion of which is composed of $8^{13}$ or $10^{12}$ FNIII domains, whereas the intracellular segment contains a single
PTP domain spanning amino acids 1060 to 1296 . Therefore, it joins an expanding group of such receptors classified as type III PTPs $^{3}$ that includes PTP- $\beta,{ }^{23}$ PTP-U2, ${ }^{24}$ GLEPP $1,{ }^{25}$ and SAP$1^{26}$ from humans and DPTP10D, ${ }^{27}$ DPTP99A, ${ }^{28}$ and DPTP4E ${ }^{29}$ from Drosophila, with HPTP- $\eta$ being the unique type III PTP expressed on hematopoietic cells. These enzymes are characterized by a similar organization of their extracellular segments, which consist of a repeated array of FNIII motifs, and a single intracytoplasmic phosphatase domain. The FNIII repeats, in addition to being involved in adhesion processes, ${ }^{29}$ are also found in the extracellular regions of the receptors for interleukin-2 (IL-2), IL-4, IL-6, granulocyte-macrophage colonystimulating factor, prolactin, erythropoietin, and growth hormone. ${ }^{30}$ The DEP-1 molecule has been implicated in contact inhibition of cell growth because it is upregulated in dense cell cultures although its upregulation is initiated before saturation density is reached. In addition, it has been described that the expression level of HPTP- $\eta$ was altered when the HL-60 cells were exposed to differentiating compounds such as dimethyl sulfoxide and 12-O-tetra decanoyl phorbol 13-acetate, suggesting that this gene might be involved in the differentiating processes for granulocyte or monocyte/macrophage lineages in these cells. ${ }^{11}$

The CD45 molecule, the principal protein tyrosine phosphatase present on the membrane of hematopoietic cells, is capable of regulating signal transduction and functional responses, ${ }^{7-9}$ because in T lymphocytes, CD45 crosslinking inhibits inositol phosphate production, calcium flux, and proliferation. ${ }^{31}$ The ability of CD45 to modulate signals transduced by CD3 correlates with its ability to inhibit the tyrosine phosphorylation of some intracellular protein substrates. ${ }^{31,32}$ Once we showed that the molecule recognized by the $143-41 \mathrm{MoAb}$ is a membrane protein tyrosine phosphatase, we were interested to know whether this molecule could influence the signal transduction through the antigen receptor. The most striking fact of this analysis was the observation that the crosslinking of CD148 alone was able to induce a clear increase in $\left[\mathrm{Ca}^{2+}\right]_{\mathrm{i}}$. This phenomenon was not observed after CD45 crosslinking. The kinetic of the process was similar to the $\mathrm{Ca}^{2+}$ mobilization induced after CD3 crosslinking, although the lag time was clearly more prolonged in the case of CD148. Another difference was based on the intensity of the response. The CD148 crosslinking produced both a lower level of $\left[\mathrm{Ca}^{2+}\right]_{i}$ mobilization and a lower number of responding cells (39\% v 69\%). In fact, CD148 crosslinking was able to decrease the $\mathrm{Ca}^{2+}$ mobilization in $35 \%$ of the cells responding to CD3 (69\%), a percentage similar to the percentage of cells responding to CD148 crosslinking (39\%).

Concerning the mechanisms involved in this process, we consider it plausible that tyrosine phosphorylation could be involved because the cocrosslinking with CD45 or the presence of genistein were able to abolish the response induced by CD148. This assumption was proven to be correct, because after CD148 crosslinking a clear pattern of tyrosine phosphorylation could be observed. Especially interesting was the observation that CD148 crosslinking was able to induce tyrosine phosphorylation of PLC- $\gamma 1$. Although it may seem contradictory that a protein tyrosine phosphatase is able to induce tyrosine phosphorylation, a similar situation has been described for the molecule 
CD45. ${ }^{33-35}$ In this case, the association of p56lck with the cytoplasmic tail of $\mathrm{CD} 45^{35,36}$ results in an increase in the catalytic activity of the PTK after CD45 crosslinking. ${ }^{37}$ In a similar way, the existence of an association of CD148 with some PTK able to mediate the observed increase in $\mathrm{Ca}^{2+}$, could be considered. This PTK could be activated through dephosphorylation by the tyrosine phosphatase domain of CD148, similar to the way in which CD45 dephosphorylates Y505 on p56lck, turning the inactive protein into an active PTK. ${ }^{38}$

In addition, we have also observed that CD148 was able to inhibit the $\mathrm{Ca}^{2+}$ mobilization induced by $\mathrm{CD} 3 \mathrm{MoAb}$ when both molecules were cocrosslinked. This could have occurred by bringing the PTP domain of CD148 into close proximity with the cytoplasmic domain of a signaling molecule. In this way its activity could be triggered by changing the phosphorylation status of critical tyrosine residues used in signal transduction, as has been described with CD45. ${ }^{31,32}$ Although Shivnan et al ${ }^{39}$ have suggested that some of the results of coclustering experiments with CD45 may have to do with interfering with CD3 clustering, we have observed no interference in our experimental model when CD3 was cocrosslinked with lymphocyte function-associated antigen (data not shown), thus discarding an unspecific effect. However, whether the inhibition of CD148 on CD3 signaling is based on the phosphorylation or the dephosphorylation of some substrate(s) remains to be determined. In spite of the tyrosine phosphatase activity of CD148 no general dephosphorylation was observed after CD3 and CD148 cocrosslinking. In fact, only a very selective inhibition of a few substrates was detected, the most significant being the dephosphorylation of PLC- $\gamma$. This dephosphorylation could account for the inhibition of $\mathrm{Ca}^{2+}$ mobilization, in a way similar to CD45. ${ }^{31,32}$ In this case also few very selective dephosphorylation events have been related by CD3 signaling inhibition. ${ }^{33,34}$ It could seem contradictory that the cocrosslinking of CD148 and CD3 results in no signal whereas engagement of either molecule by itself causes significant signal transduction events to occur. Although we have no definitive data to explain these facts, a possible explanation could be that the kinase activity activated through CD148 crosslinking would be modified after cocrosslinking CD148 with CD3, whereas the own phosphatase activity of CD148 would remain intact. If this were the case, the activation of PLC- $\gamma$ by CD3 would be decreased by the phosphatase activity of CD148 and it would not be compensated by the activation through CD148. The net result of this process would be a diminished activation of PLC- $\gamma$ and consequently the inhibition of $\mathrm{Ca}^{2+}$ mobilization. On the other hand, our results also show an increase in the phosphorylation of some substrates after CD3 and CD148 cocrosslinking. This fact was particularly evident in a $56-\mathrm{kD}$ substrate. Corvaïa et $\mathrm{al}^{40}$ have also described an increase in protein tyrosine phosphorylation of some substrates after cotriggering human monocytes with FcyRI or Fc $\gamma$ RII with CD45. Thus, the possibility that a specific phosphorylation of some substrate could be responsible for the inhibition of the signaling process through CD3 could not be ruled out.

In conclusion, in the present report we have shown a functional role for a recently described membrane protein tyrosine phosphatase, which is involved in the signaling pathways of T lymphocytes, opening a new avenue of research into the signal transduction pathways of these cells.

\section{ACKNOWLEDGMENT}

We thank Drs Honda and Hirai for kindly providing the hp21 cDNA clone, Dr P. Engel for his collaboration in the transfection assays and Dr M. Simarro for her help in the tyrosine phosphorylation analysis.

\section{REFERENCES}

1. Sun H, Tonks NK: The co-ordinated action of protein tyrosine phosphatases and kinases in cell signaling. Trends Biochem Sci 19:480, 1994

2. Hunter T: Protein kinases and phosphatases: The yin and yang of protein phosphorylation and signaling. Cell 80:225, 1995

3. Fisher EH, Charbonneau H, Tonks NK: Protein tyrosine phosphatases: A diverse family of intracellular and transmembrane enzymes. Science 253:401, 1991

4. Stone RL, Dixon JE: Protein-tyrosine phosphatases. J Biol Chem 269:31323, 1994

5. Zenner G, Hausen JD, Burn P, Mustelin T: Towards unraveling the complexity of T cell signal transduction. Bioessays 17:967, 1995

6. Okumura M, Thomas ML: Regulation of immune function by protein tyrosine phosphatases. Curr Opin Immunol 7:312, 1995

7. Lebdetter JA, Tonks NK, Fisher EH, Clark EA: CD45 regulates signal transduction and lymphocyte activation by specific association with receptor molecules on T and B cells. Proc Natl Acad Sci USA $85: 8628,1988$

8. Martorell J, Vilella R, Borche L, Rojo I, Vives J: A second signal for $\mathrm{T}$ cell mitogenesis provided by monoclonal antibodies CD45 (T200). Eur J Immunol 17:1447, 1987

9. Alsinet E, Inglés-Esteve J, Vilella R, Lozano F, Milà J, Rojo I, Martorell J, Vives J, Gayà A: Differential effects of anti-CD45 monoclonal antibody on human B cell proliferation: A monoclonal antibody recognizing a neuraminidase-sensitive epitope of the T200 molecule enhances anti-immunoglobulin-induced proliferation. Eur $\mathbf{J}$ Immunol 20:2801,1990

10. Schraven B, Hegen M, Autschbatch F, Gayá A, Schwartz C, Meuer S: Cluster Report CD148, in Kishimoto et al (eds): Leucocyte Typing VI, New York, NY, Garland Publishing, 1998 (in press)

11. Honda H, Shibuya M, Chiba S, Yazaki Y, Hirai H: Identification of novel protein-tyrosine phosphatases in a human leukemia cell line, F-36P. Leukemia 7:742, 1993

12. Honda H, Inazawa J, Nishida J, Yazaki Y, Hirai H: Molecular cloning, characterization, and chromosomal localization of a novel protein-tyrosine phosphatase, HPTP- $\eta$. Blood 84:4186, 1994

13. Östman A, Yang Q, Tonks NK: Expression of DEP-1, a receptor-like protein tyrosine-phosphatase, is enhanced with increasing cell density. Proc Natl Acad Sci USA 91:9680, 1994

14. Vilella R, Yagüe J, Vives J: Monoclonal antibody against HLA-Aw32+A25. Is HLA-Aw32 an allele with no unique antigenic determinant? Hum Immunol 6:53, 1983

15. Juan M, Vilella R, Milá J, Yagüe J , Miralles A, Campbell KS, Friedich RJ, Cambier J, Vives J, De Fougerolles AR, Springer TA: CDw50 and ICAM-3: Two names for the same molecule. Eur J Immunol 23:1508, 1993

16. Wacholtz MC, Lipsky PE: Anti-CD3-stimulated $\mathrm{Ca}^{2+}$ signal in individual human peripheral $\mathrm{T}$ cells. Activation correlates with a sustained increase in intracellular $\mathrm{Ca}^{2+}$. J Immunol 150:5338, 1993

17. Rooney TA, Sass EJ, Thomas AP: Characterization of cytosolic calcium oscillations induced by phenylephrine and vasopressin in single fura-2-loaded hepatocytes. J Biol Chem 264:17131, 1989

18. Grynkiewicz G, Peonie M, Tsien RY: A new generation of $\mathrm{Ca}^{2+}$ indicators with greatly improved fluorescence properties. J Biol Chem 260:3440, 1985

19. Juan M, Viñas O, Pino-Otín MR, Places L, Martínez-Cáceres E, Barceló JJ, Miralles A, Vilella R, de la Fuente MA, Vives J, Yagüe J, Gayà A: CD50 (Intercellular Adhesion Molecule 3) stimulation induces 
calcium mobilization and tyrosine phosphorylation through p59 fyn and p56 lck in Jurkat T cell line. J Exp Med 179:1747, 1994

20. Volarevic S, Niklinska BB, Burns CM, Yamada H, June CH, Dumont FJ, Ashwell JD: The CD45 tyrosine phosphatase regulates phosphotyrosine homeostasis and its loss reveals a novel pattern of late T cell receptor-induced $\mathrm{Ca}^{2+}$ oscillations. J Exp Med 176:835, 1992

21. Streuli M: Protein tyrosine phosphatases in signaling. Curr Opin Cell Biol 8:182, 1996

22. Stein H, Schwarting R, Niedobitek G: Cluster report: CD26, in Knapp W, Dörken B, Gilks WR, Rieber EP, Schmidt RE, Stein H, von dem Borne AEGKr (eds): Leucocyte Typing IV. Oxford, UK, Oxford University Press, 1989, p 412

23. Krueger NX, Streuli M, Saito H: Structural diversity and evolution of human receptor-like protein tyrosine phosphatases. EMBO J 9:3241, 1990

24. Seimiya H, Sawabe T, Inazawa J, Tsuruo T: Cloning, expression and chromosomal localization of a novel gene for protein tyrosine phosphatase (PTP-U2) induced by various differentiation-inducing agents. Oncogene 10:1731, 1995

25. Wiggins RC, Wiggins JE, Goyal M, Wharram BL, Thomas PE: Molecular cloning of cDNAs encoding human GLEPP1, a membrane protein tyrosine phosphatase: Characterization of the GLEPP1 protein distribution in human kidney and assignment of the GLEPP1 gene to human chromosome 12p12-p13. Genomics 27:174, 1995

26. Matozaki T, Suzuki T, Uchida T, Inazawa J, Ariyama T, Matsuda K, Horita K, Noguchi H, Mizuno H, Sakamoto C, Kasuga M: Molecular cloning of a human transmembrane-type protein tyrosine phosphatase and its expression in gastrointestinal cancers. J Biol Chem 269:2075, 1994

27. Tian S-S, Tsoulfas P, Zinn K: Three receptor-linked proteintyrosine phosphatases are selectively expressed on central nervous axons in the Drosophila embryo. Cell 67:675, 1992

28. Oon SH, Hong A, Yang X, Chia W: Alternative splicing in a novel tyrosine phosphatase gene (DPTP4E) of Drosophila melanogaster generates two large receptor-like proteins which differ in their carboxy termini. J Biol Chem 268:23964, 1993

29. Cunningham BA, Hemperly JJ, Murray BA, Prediger EA, Brackenbury R, Edelman GM: Neural cell adhesion molecule: Structure, immunoglobulin-like domains, cell surface modulation, and alternative RNA splicing. Science 236:799, 1987
30. Patthy L: Homology of a domain of the growth hormone/ prolactin receptor family with type III modules of fibronectin. Cell $61: 13,1990$

31. Lebdeter JA, Schieven GL, Uckun FM, Imboden JB: CD45 crosslinking regulates phospholipase $\mathrm{C}$ activation and tyrosine phosphorylation of specific substrates in CD3/Ti-stimulated T cells. J Immunol 146:1577, 1991

32. Kanner SB, Deans JP, Ledbetter JA: Regulation of CD3-induced phospholipase C-gamma 1 (PLC $\gamma 1$ ) tyrosine phosphorylation by CD4 and CD45 receptors. Immunology 75:441, 1992

33. Wagner N, Engel P, Tedder TF: Regulation of the tyrosine kinase-dependent adhesion pathway in human lymphocytes through CD45. J Immunol 150:4887, 1993

34. Arendt CW, Hsi G, Ostergaard HL: Immobilized antibodies to CD45 induce rapid morphologic changes and increased tyrosine phosphorylation of p56lck-associated proteins in T cells. J Immunol 155:5095, 1995

35. Xu X, Chong AS-F: Crosslinking of CD45 on NK cells stimulates $\mathrm{p} 561 \mathrm{ck}-$ mediated tyrosine phosphorylation and IFN- $\gamma$ production. J Immunol 155:5241, 1995

36. Schraven B, Kirchgessner H, Gaber B, Samstag Y, Meuer S: A functional complex is formed in human $\mathrm{T}$ lymphocytes between the protein tyrosine phosphatase $\mathrm{CD} 45$, the protein tyrosine kinase p561ck and pp32, a possible common substrate. Eur J Immunol 21:2469, 1991

37. Cardine AM, Maridonneau-Parini Y, Fisher S: Activation and internalization of p56lck upon CD45 triggering of Jurkat cells. Eur J Immunol 24:1255, 1994

38. Mustelin T, Coggeshall KM, Altman A: Rapid activation of the T-cell tyrosine protein kinase pp56lck by the CD45 phosphotyrosine phosphatase. Proc Natl Acad Sci USA 86:6302, 1989

39. Shivnan E, Biffen M, Shiroo M, Pratt E, Glennie M, Alexander D: Does co-aggregation of the CD45 and CD3 antigens inhibit $\mathrm{T}$ cell antigen receptor complex-mediated activation of phospholipase $\mathrm{C}$ and protein kinase C? Eur J Immunol 22:1055, 1992

40. Corvaïa N, Reischl IG, Kroemer E, Muddle GC: Modulation of Fc $\gamma$ receptor-mediated early events by the tyrosine phosphatase CD45 in primary human monocytes. Consequence for interleukin-6 production. Eur J Immunol 25:738, 1995 